\title{
Metabolism of Saturated $1-{ }^{14} \mathrm{C}$-Labelled Fatty Acids in the Silkworm Bombyx mori L.
}

\author{
BY S. SRIDHARA,* U. RAVI RAO AND J. V. BHAT \\ Fermentation Technology Laboratory, Indian Institute of Science, Bangalore 12, India
}

(Received 4 May 1965)

\begin{abstract}
1. Only a small percentage of $1{ }^{14} \mathrm{C}$-labelled saturated fatty acids injected in the silkworm is respired as carbon dioxide. 2. The rate of utilization of fatty acids is low both at the larval and pupal stages. 3. The insect has the ability to elongate $\mathrm{C}_{12}$ and $\mathrm{C}_{16}$ saturated fatty acids and to desaturate $\mathrm{C}_{18}$ saturated fatty acids. 4. Much of the administered radioactivity is found in the triglyceride fraction, followed by the phospholipid and diglyceride fractions. 5. Diglycerides seem to be the transport form of fatty acids. 6. The insect seems to metabolize both natural and unnatural fatty acids in the same manner.
\end{abstract}

Although earlier respiratory quotient measurements implicated fat as the energy source in several insect species (Weis-Fogh, 1952), our studies indicate that this may not be so in the silkworm (Sridhara, 1965; Sridhara \& Bhat, 1965c). Chino \& Gilbert (1964), working with Hyalophora silkmoths, showed that injected palmitic acid is carried mainly as diglycerides attached to a protein, whereas newly synthesized fatty acids from $[1.14 \mathrm{C}]$ acetate were found in the monoglyceride fraction of silkworm pupal lipids (Sridhara \& Bhat, 1965a). These raised questions as to whether: (i) the silkworm metabolizes preformed and derived fatty acids separately; (ii) differences exist between larval and pupal stages in fatty acid metabolism; (iii) fatty acids are utilized as energy source during metamorphosis and pupal development. The present paper describes experiments designed to answer these questions by studying the fate of saturated $1-{ }^{14} \mathrm{C}$-labelled fatty acids.

\section{MATERIALS AND METHODS}

Treatment and extraction of insects. Mature silkworm larvae of Bombyx mori L. weighing 1-1-1.2g. and 5-day-old pupae weighing $0.5-0.6 \mathrm{~g}$. were used. Larvae and pupae of approximately the same weight were used in each experiment, but weights differed slightly from experiment to experiment. The methods adopted for injection, lipid extraction and fractionation, fatty acid analysis and isolation of different organs have been detailed by Sridhara \& Bhat $(1964,1965 a)$. For the intestine the whole gut was used and integument was free of adhering muscle. $[1-14 \mathrm{C}]-$ Palmitic acid (sp. activity $145 \mu \mathrm{c} / \mathrm{mg}$.), -stearic acid (sp.

\footnotetext{
* Present address: Department of Biological Chemistry, The Medical Centre, University of California at Los Angeles, Los Angeles 24, Calif., U.S.A.
}

activity $43 \cdot 3 \mu \mathrm{c} / \mathrm{mg}$.) and -lauric acid (sp. activity $13 \mu \mathrm{c} /$ mg.) were obtained from The Radiochemical Centre, Amersham, Bucks. Stock solutions of these fatty acids were prepared in ethanol. Just before use, ethanol was evaporated and the fatty acid was taken up as a dispersion in Tween 80 , which was used as a $2 \%$ suspension in phosphate buffer, $\mathrm{pH} 7 \cdot 4$.

Estimation of expired ${ }^{14} \mathrm{CO}_{2}$. Larvae 3 or 4 days after the fourth moult and weighing $0 \cdot 5-0 \cdot 6 \mathrm{~g}$. were injected with $0.5 \mu \mathrm{C}$ of the fatty acid, and were allowed to feed on mulberry leaves for $1 \mathrm{hr}$. and then transferred to separate Warburg flasks (15 ml.). The $\mathrm{CO}_{2}$ expired was absorbed into $20 \%(w / v) \mathrm{KOH}$ contained in the centre well. After the times indicated in the Tables, commencing from the removal of larvae from the mulberry leaves, the alkali was transferred to centrifuge tubes by repeated washing and the carbonate was precipitated with $\mathrm{BaCl}_{2}$ and allowed to stand overnight. The precipitate was centrifuged down, washed twice with water and twice with ethanol, dried, weighed and plated for counting.

\section{RESULTS}

Tables 1, 2 and 3 show the results of experiments carried out with lauric acid, palmitic acid and stearic acid respectively. Subsequent pupation of the larvae after the injection of radioactive fatty acid is indicated in the first column of each Table and is represented as $\infty$. Carbon dioxide could be collected only for $8 \mathrm{hr}$. since the larvae became weak and the respiration rate decreased considerably thereafter. However, such larvae, if allowed to feed, grew just as well as the normal ones.

The results show that the amount of radioactivity released as carbon dioxide is low, and this compares favourably with the diminution of radioactivity recoverable from the lipid. The absence of absolute correspondence is due to the use of different larvae, of different ages, and different timings. The 


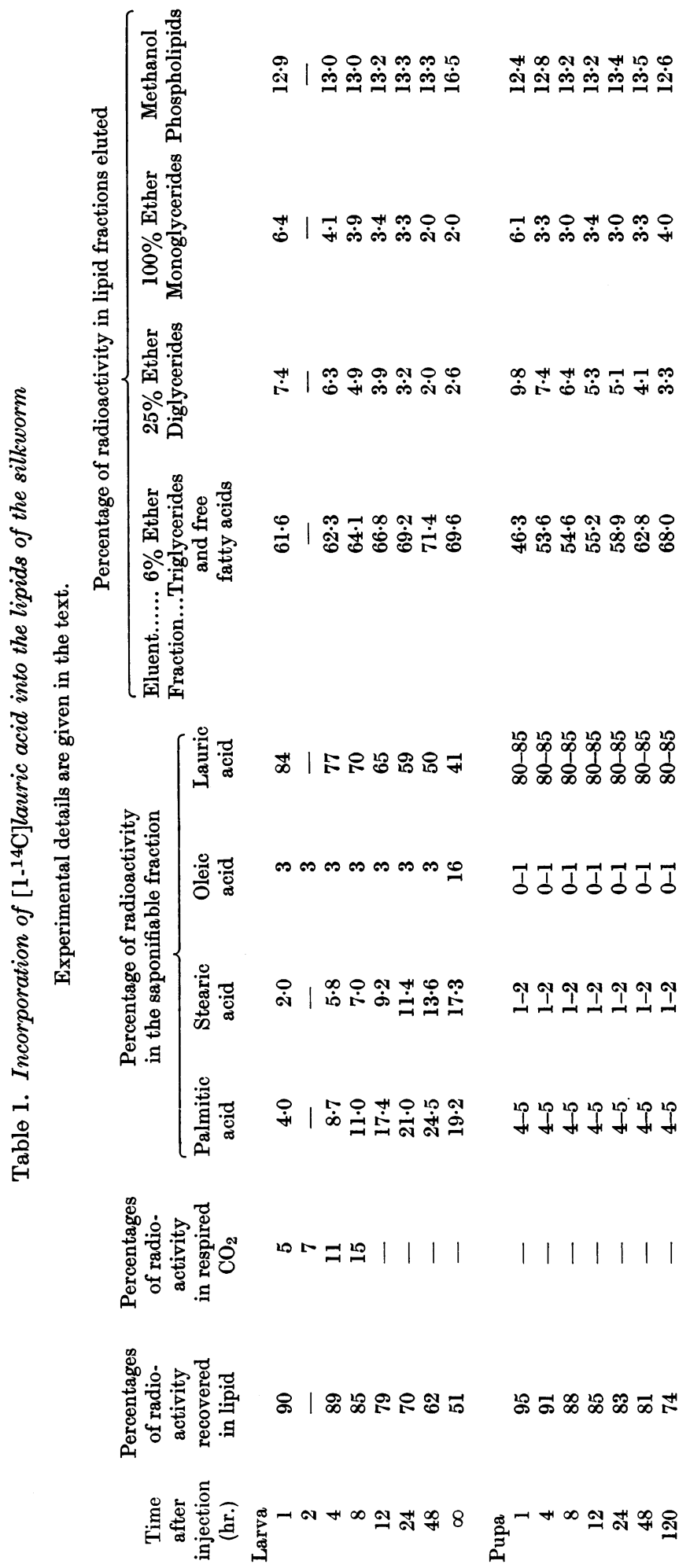




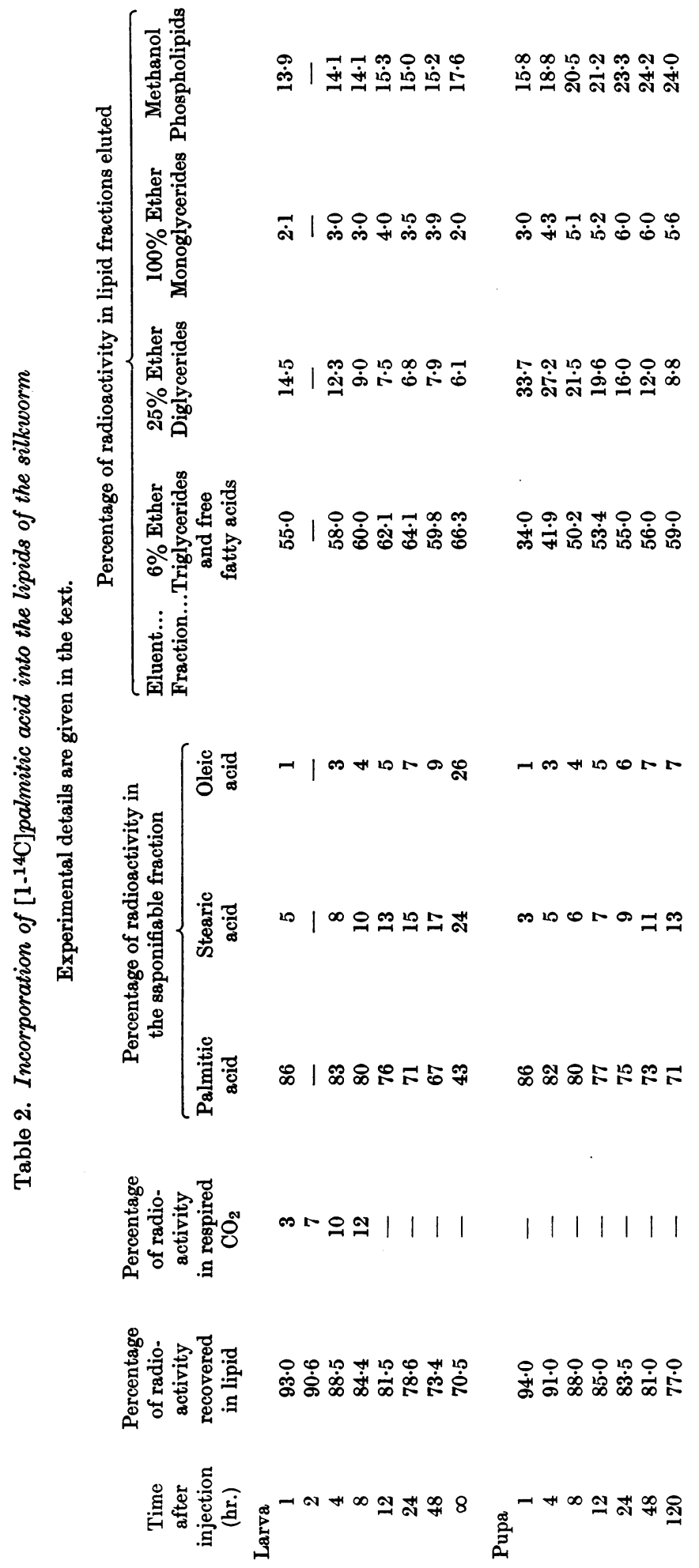




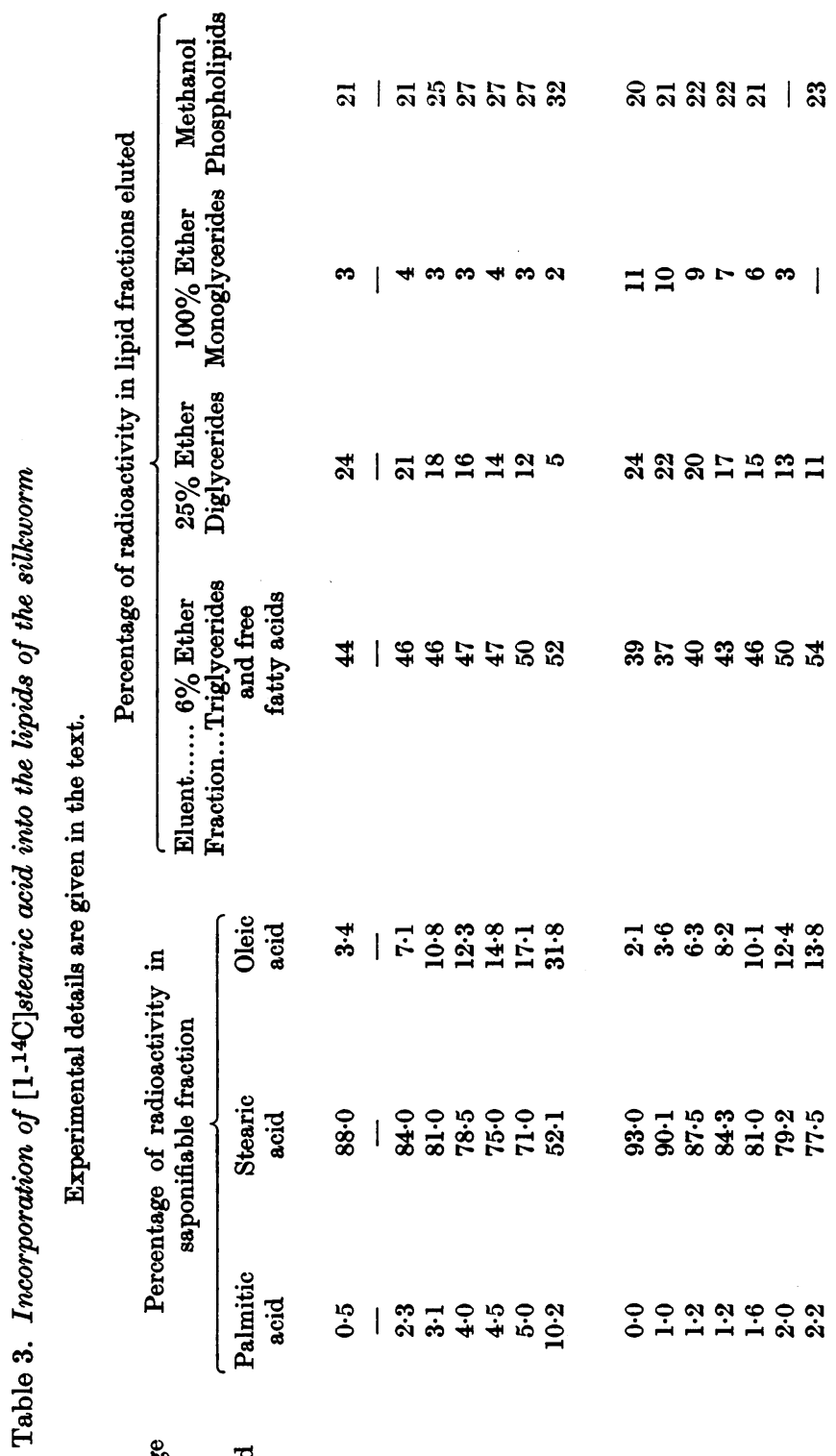

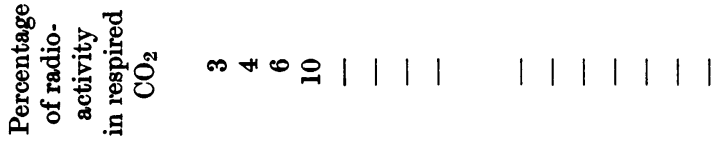

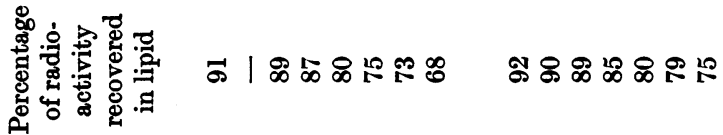

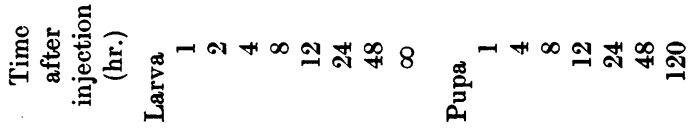


amount of radioactivity lost during the pupal stage is much lower than that during the larval stage. In all cases $50-60 \%$ of the administered radioactivity is found in the lipid fraction even after 8 days of administration at the larval stage, and about $70 \%$ is recovered at the pupal stage after 5 days.

The amounts of radioactivity found in the various fatty acids show that the rate of conversion into other fatty acids depends on the fatty acid used. Stearic acid is converted to a greater extent into oleic than into palmitic acid, conversion of palmitic acid into stearic acid is much greater than that into oleic acid, and lauric acid is converted mainly into palmitic acid and stearic acid. However, in all cases the rate of conversion at the pupal stage is much lower than at the larval stage.

The percentage of radioactivity that is eluted in the various fractions is shown in the respective Tables. The fractions eluted with light petroleum, $1 \%(\mathrm{v} / \mathrm{v})$ ether in light petroleum and $10 \%(\mathrm{v} / \mathrm{v})$ ether in light petroleum respectively have not been included, since in all the cases the percentage of radioactivity eluted was equal to or less than $1 \cdot 0$. Within $1 \mathrm{hr}$. after injection most of the radioactivity in the lipid is distributed among the triglyceride, diglyceride and phospholipid fractions. The amount of radioactivity recovered in the diglycerides was small with $\left[1-{ }^{14} \mathrm{C}\right]$ lauric acid, higher with $\left[1-{ }^{14} \mathrm{C}\right]$ stearic acid and highest with $\left[1-{ }^{14} \mathrm{C}\right]$ palmitic acid. The percentage of radioactivity found in the diglyceride fraction is slightly higher at the pupal stage. The percentage of radioactivity found in the phospholipid fraction at both stages is somewhat higher with $\left[1-{ }^{14} \mathrm{C}\right]$ stearic acid than with the other two labelled acids. The high radioactivity found in the diglyceride fraction at the beginning decreases slowly with time, whereas that of the triglyceride fraction increases.

Table 4 shows the distribution of the radioactivity among different organs of the silkworm $8 \mathrm{hr}$. and $24 \mathrm{hr}$. after the administration of the fatty acid. The pattern of distribution appears to be similar for all fatty acids in that the fat body carries the maximum activity, followed by integuments, silk glands and intestines.

\section{DISCUSSION}

The retention of a considerable amount of injected radioactivity in the lipid and expiration of only small quantity thereof in carbon dioxide indicates a low utilization of the labelled fatty acid by the insect. This is further supported by the negligible utilization of the injected fatty acid both during metamorphosis and pupal development. The decrease in the amount of ${ }^{14} \mathrm{C}$ recovered in carbon dioxide might be due to the dilution of the substrate or conversion of the fatty acid into a non-utilizable form.

In the rat, which is known to utilize fat as the energy source, on the other hand, about $50 \%$ of [1-14C]palmitic acid, -trilaurin and -tripalmitin appears as carbon dioxide within $2 \mathrm{hr}$. and as much as $70 \%$ within $3.5 \mathrm{hr}$. (Geyer, Chipman \& Stare, 1948; Lerner, Chaikoff, Entenmann \& Dauben, 1949; McCalla, Gates \& Gordon, 1957). This finding, when considered together with the previous observation of the inability of silkworm intestinal mitochondria to oxidize fatty acids (Sridhara, 1965) on the one hand and the non-interconversion of fat and carbohydrate in this insect (Sridhara \& Bhat, 1965c) on the other, is indicative of the unsuitability of fat as a source of energy for this insect at least at the stages studied. Domrose \& Gilbert (1964) have shown that fat is utilized by males of $H$. cecropia only as adults, whereas females use fat both during adult development and adult life.

The fact that the radioactivity of the administered fatty acid is found in other fatty acids also shows that the silkworm is capable not only of elongating saturated fatty acids but also of desaturating stearic acid to oleic acid. The recovery of radioactivity from $\left[1 .{ }^{14} \mathrm{C}\right]$ stearic acid in palmitic acid as well as that of radioactivity from $\left[1-{ }^{14} \mathrm{C}\right]$ lauric acid in palmitic acid may be due to the fact that the ${ }^{14} \mathrm{C}$ of $\left[1-{ }^{14} \mathrm{C}\right]$ stearic acid enters the $\mathrm{C}_{2}$

Table 4. Incorporation of $\left[1{ }^{14} \mathrm{C}\right]$-stearic acid, -palmitic acid and -lauric acid into the lipids of the tissues of the silkworm

\begin{tabular}{|c|c|c|c|c|c|c|}
\hline \multirow[b]{3}{*}{$\begin{array}{c}\text { Tissue } \\
\text { Intestines }\end{array}$} & \multicolumn{6}{|c|}{ Percentage distribution of radioactivity } \\
\hline & \multicolumn{2}{|c|}{$\left[1-{ }^{14} \mathrm{C}\right]$ Stearic acid } & \multicolumn{2}{|c|}{$[1.14 \mathrm{C}]$ Palmitic acid } & \multicolumn{2}{|c|}{$[1.14 \mathrm{C}]$ Lauric acid } \\
\hline & $\begin{array}{c}\text { After } 8 \mathrm{hr} . \\
9 \cdot 5\end{array}$ & $\begin{array}{c}\text { After } 24 \mathrm{hr} \text {. } \\
11 \cdot 3\end{array}$ & $\begin{array}{c}\text { After } 8 \mathrm{hr} . \\
10 \cdot 5\end{array}$ & $\begin{array}{c}\text { After } 24 \mathrm{hr} \text {. } \\
9 \cdot 8\end{array}$ & $\begin{array}{c}\text { After } 8 \mathrm{hr} . \\
7.5\end{array}$ & $\begin{array}{c}\text { After } 24 \mathrm{hr} \text {. } \\
6.8\end{array}$ \\
\hline Silk glands & $6 \cdot 3$ & $7 \cdot 3$ & $10 \cdot 6$ & $11 \cdot 4$ & $7 \cdot 6$ & $7 \cdot 8$ \\
\hline Fat body & $47 \cdot 2$ & $46 \cdot 1$ & $52 \cdot 8$ & $\mathbf{5 4} \cdot \mathbf{5}$ & $61 \cdot 5$ & $61 \cdot 4$ \\
\hline Integuments & $23 \cdot 6$ & $25 \cdot 2$ & $16 \cdot 8$ & $17 \cdot 2$ & $16 \cdot 5$ & $16 \cdot 7$ \\
\hline
\end{tabular}


pool and is used for the new synthesis of these fatty acids. The observation that more radioactivity passes into oleic acid during metamorphosis is in conformity with that made previously with $[1.14 \mathrm{C}]$ acetate and with respect to the increase in oleic acid during metamorphosis at the expense of saturated fatty acids (Sridhara \& Bhat, 1965b). Another conclusion that emerges from these results is that the silkworm metabolizes an unnatural fatty acid (lauric acid is not present in the silkworm) in a manner identical with that used for the natural acids, and that pupae metabolize fatty acids more slowly than do larvae.

The recovery of a high percentage of radioactivity in the diglyceride fraction released from the fat body under the influence of some factor in the haemolymph (Teitz, 1962; Chino \& Gilbert, 1965a) is not surprising in view of the fact that diglycerides are the transport form of lipids in the three insects studied. In the silkworm, if one considers the specific activity of the diglyceride fraction after injection with [1-14C]-palmitic acid and -stearic acid, it is always equal to or higher than that of triglycerides formed during the first $2 \mathrm{hr}$. This means that the fat body endergonically carries out the synthesis of triglycerides via diglycerides and releases fat from fat body as diglycerides, and this may explain the low rate of utilization of fatty acids. In mammals it has been definitely shown that plasma unesterified fatty acid is the transport form of lipid available for tissues as substrate for oxidation, and that when its concentration decreases fatty acid oxidation is inhibited (Lossow \& Chaikoff, 1955; McCalla et al. 1957; Fredrickson \& Gordon, 1958; Steinberg, 1963). If this theory holds good for insects also (unesterified fatty acid has been found in many insects including the silkworm; Sridhara \& Bhat, 1965b), then it may be postulated that the fatty acid administered is immediately converted into diglycerides, triglycerides and phospholipids, thus obviating the need for its existence as unesterified fatty acid in blood. The hypothesis would also explain the enhanced radioactivity of the carbon dioxide released at the beginning of the experiment. In fact, Chino \& Gilbert (1965b) have shown that fatty acids are esterified to diglycerides and triglycerides at a fast rate in the fat body of H. cecropia silkmoths.
It is only in the distribution of radioactivity among various fractions that some differences are seen between preformed and derived fatty acids. The radioactivity of fatty acids synthesized from $\left[1-{ }^{14} \mathrm{C}\right]$ acetate is greater in the monoglyceride fraction at the pupal stage; other differences were also observed between the larval and pupal stages (Sridhara \& Bhat, 1965a). But no such differences are observed with the labelled fatty acids. This may be either due to the fact that the insect has to deal with all the different fatty acids synthesized from $\left[1-{ }^{14} \mathrm{C}\right]$ acetate in contradistinction to only one fatty acid administered in the present work, or due to the differences in the mode of transport itself. However, the pattern of distribution of the radioactivity among different tissues is not inconsistent with that observed previously in connexion with the metabolism of $\left[1-{ }^{14} \mathrm{C}\right]$ acetate (Sridhara \& Bhat, 1965a).

This work was supported by grants from U.S. Public Law 480 funds. Our thanks are due to Professor P. S. Sarma for the use of counters.

\section{REFERENCES}

Chino, H. \& Gilbert, L. I. (1964). Science, 143, 359.

Chino, H. \& Gilbert, L. I. (1965a). Biochim. biophys. Acta, 98, 94.

Chino, H. \& Gilbert, L. I. (1965b). J. Insect Physiol. 11, 287.

Domrose, K. A. \& Gilbert, L. I. (1964). J. exp. Biol. 41, 573.

Fredrickson, D. S. \& Gordon, R. S., jun. (1958). Physiol. Rev. 38, 585.

Geyer, R. P., Chipman, J. \& Stare, F. J. (1948). J. biol. Chem. 176, 1469.

Lerner, S. R., Chaikoff, I. L., Entenmann, C. \& Dauben, W. G. (1949). Science, 109, 13.

Lossow, W. J. \& Chaikoff, I. L. (1955). Arch. Biochem. Biophys. 57, 23.

McCalla, C., Gates, H. S. \& Gordon, R. S. (1957). Arch. Biochem. Biophys. 71, 346.

Sridhara, S. (1965). J. Insect Physiol. 11, 33.

Sridhara, S. \& Bhat, J. V. (1964). Biochem. J. 91, 120.

Sridhara, S. \& Bhat, J. V. (1965a). Biochem. J. 94, 700.

Sridhara, S. \& Bhat, J. V. (1965b). J. Insect Physiol. 11, 493.

Sridhara, S. \& Bhat, J. V. (1965c). Life Sci. 4, 979.

Steinberg, D. (1963). In Control of Lipid Metabolism, p. 111. Ed. by Grant, J. K. New York: Academic Press Inc.

Teitz, A. (1962). J. Lipid Res. 3, 421.

Weis-Fogh, T. (1952). Phil. Trans. B, 237, 1. 